\title{
THE INFLUENCE OF RIND OF WATERMELON IN THE HEAT TRANSFER CALCULATION
}

\author{
Carson L. Wiles $^{1 *}$, Sathish K. Gurupatham ${ }^{1}$, Valmiki K. Sooklal ${ }^{1}$, Kim Hanseul ${ }^{1}$, Jonathon Kitchel $^{1}$ \\ ${ }^{1}$ Kennesaw State University, Marietta, GA 30060, USA
}

\begin{abstract}
The knowledge of temperature field in any product is essential for the design and optimization of the conductive heat transfer from its boundary for the optimum storage conditions. It becomes even more critical for fruits since they require to be maintained slightly higher than the freezing point of it, constantly, to avoid the damages at a premature state. It is interesting to observe that the rind and the juicy part of the fruit have different thermal conductivity and the heat transfer calculations assume it to be the same. This paper investigates the differences in heat transfer calculations arising due to this assumption inside a watermelon that is subjected to a varied temperature of the surrounding condition. The experimental results show that there is a significant change in the heat transfer and the temperature drop across the rind of the watermelon.
\end{abstract}

KEY WORDS: Transient Conduction, Heat Transfer, Thermal Conductivity, Pre-cooling

\section{INTRODUCTION}

The cooling of food products is a process in which their temperature is reduced to the required storage temperature in order to prevent their early spoilage and also to maintain their quality. The phenomena involved in food processing and preservation are closely tied to thermodynamics, transport, reaction kinetics, and other principles of chemical engineering science $[1,2,3]$. The temperature field in the medium resulting from conduction is important for every process that involves unsteady heat transfer [4].

At lower temperatures, fruits are susceptible to chilling injury and decay [5,6]. Accurate thermal conductivity, density, viscosity, and specific heat data for fruits and fruit juices are needed for a variety of research and engineering applications [7]. This includes designing food processes and processing equipment, the control of products, filters and mixers, quality evaluation and an understanding of the structure of food and raw agricultural materials which are essential for the food industry [8]. Modelling, optimization and automation of food processes is difficult because of the complexity of the raw materials and products that are involved. Watermelon is cultivated in large areas and it is one of the most important and economical crops due to being very rich in nutrition [9]. The juice and pulp are used for human consumption whereas the rind and seeds are considered solid wastes [10]. There are data available from the literature on the physical and engineering properties of many agricultural products $[11,12,13]$. Generally, watermelons are not required to be refrigerated when handled domestically but is needed during export shipment to extend the shelf-life [14]. Pre-storage conditioning at $26^{\circ} \mathrm{C}$ for 4 days reduces chilling injury and increases the percentage of marketable fruit following the storage process [15]. There are not many literatures on thermophysical properties of individual fruit components. However, Chen et al investigated the thermophysical properties of individual kiwifruit components such as skin, flesh, and core.

There is no literature available for understanding the influence of the rind of a watermelon in the heat transfer process. The thermal properties of water are assumed for the temperature distribution predictions inside the fruit

*Corresponding Author: cwiles3@students.kennesaw.edu 
during its cooling. There are not many literatures for the storage of fruits during the storing and shipping processes. In this paper, the temperature distribution across the radius for a thickness equal to the thickness of the rind of a watermelon is obtained experimentally. The results are compared with that of a theoretical calculation of temperature distribution to compare the effect of the rind in the heat transfer calculation.

The next section will describe the experimental setup and explain the procedure followed to perform the experiment. Finally, the discussion of the experimental results, and the future work are explained in the conclusion.

\section{MATERIALS AND METHODS}

To obtain the temperature distribution of the watermelon at the outer boundary of the fruit, and at the bottom of the rind inside the fruit, the following procedure was followed. Two watermelons of equal diameter $(10 \mathrm{~cm})$ and weight (14 lbs) with a similar skin color were purchased from the local market. The selected watermelons were free of significant visible defects. The same room temperature of $20.8^{\circ} \mathrm{C}$ was maintained throughout the experiment using a standard housing air conditioner.

One of the watermelons was cut into two equal parts. The cut was perpendicular to the top and bottom of the watermelon so that either stem ends are untouched. The temperature was immediately measured across the radius of the fruit at the outer boundary and at the bottom of the rind. To measure the temperature both a digital thermometer (Taylor Rotating Display Thermometer, model 9834-21) and an infra-red thermal imaging camera (E5 IR CAMERA W/ MSX 120X90 RES) were employed.
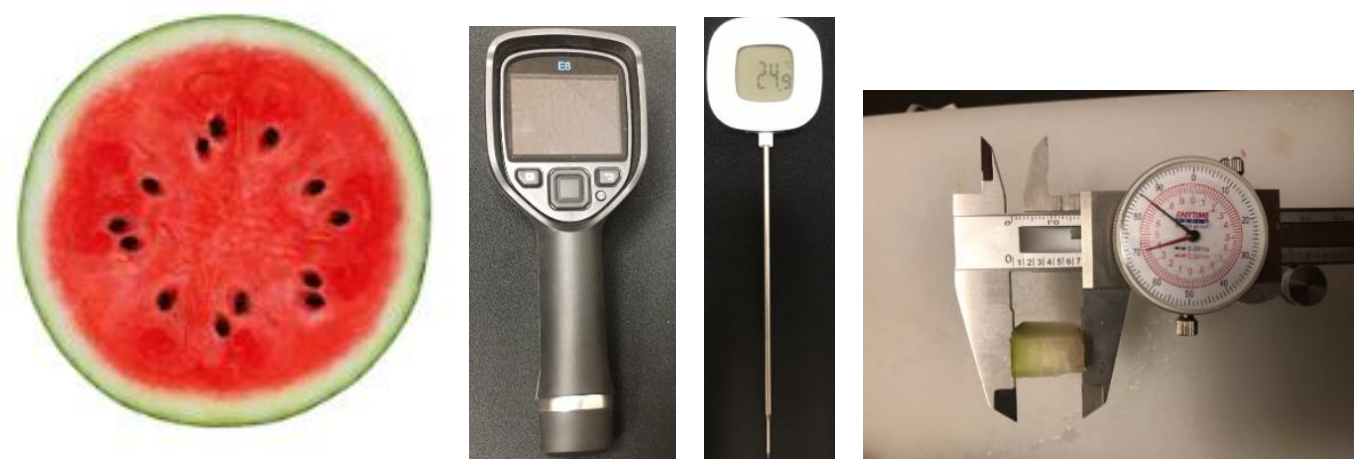

Fig. 1 The experimental setup used to take the temperature measurement across the radius of the fruit.

The thickness of the rind was measured using a shock-proof vernier caliper after identifying the transition location of the fruit where the soft, red color begins from the bottom of the rind.

The second watermelon which was at the room temperature was placed in a freezer for 52 minutes which was maintained at $-6^{\circ} \mathrm{C}$. The fruit underwent the transient heat transfer during this time by which the temperature dropped across its radius from the outer boundary of the fruit. To confirm this, after this time period, the watermelon was taken out and cut to measure its radial temperature distribution with the same procedure as followed for the first watermelon. The experiment was repeated three times with the same conditions and procedures described above for the average temperature data to obtain.

The density of the rind of the watermelon was also measured as described below. The rind of the watermelon after the experiment was cut into four equally sized and shaped pieces. Each slice was individually weighed using the Sartorius Practum scientific scale and was dropped gently into a graduated cylinder that contained 50 $\mathrm{ml}$ of water. The increase in the water level of the cylinder was recorded and hence the volume of the slice of 
the fruit was measured. The procedure was repeated for the remaining three slices to obtain the average value of the volume. The density of the fruit slice was calculated using the equation,

$$
\rho=\frac{m}{\Delta V}
$$

\section{THEORETICAL APPROACH}

The temperature at the outer boundary, and at the bottom of the rind across the radius of the fruit were theoretically calculated with the assumed thermal properties of the water for the watermelon. The calculation was also performed by applying the thermal properties from academic literature [18] and both the results were compared with the experimental results to understand the influence of the thermal properties of the rind from the heat transfer viewpoint.

\section{THEORETICAL ANALYSIS}

In the first part of the analysis, the watermelon is spherical in shape and the heat conduction in the fruit is onedimensional because of symmetry about the midpoint. The thermal properties are constant as is the case for water. The heat transfer coefficient is considered constant and uniform over the entire surface.

The properties of the watermelon are approximated by those of water at the average temperature of about $5^{\circ} \mathrm{C}$, $k=0.571 \mathrm{~W} / \mathrm{m} .{ }^{\circ} \mathrm{C}$ and

$$
\alpha=\frac{k}{\rho C_{p}}=\frac{.571}{(1000 \times 4205)}=1.357 \times 10^{-7} \frac{\mathrm{m}^{2}}{\mathrm{~s}}
$$

The Biot number is obtained as below.

$$
B i=\frac{h \times r_{o}}{k}=\frac{\left(15 \frac{W}{m^{\circ} \mathrm{C}}\right)(0.1 m)}{0.571 \frac{W}{m^{\circ} \mathrm{C}}}=2.6269
$$

The constants $\lambda_{1}$ and $A_{1}$ corresponding to this Biot number are from the cengel handbook [18], where $\lambda_{1}$ $=1.5$ and $\mathrm{A}_{1}=2.1$. The Fourier number is

$$
\tau=\frac{\alpha t}{L^{2}}=\frac{\left(1.357 \times 10^{-6} \frac{m^{2}}{s}\right)(3926 s)}{0.1 m^{2}}=0.0421
$$

Applying one-term approximate solution, the temperature at the surface of the watermelon becomes:

$$
\begin{gathered}
\theta(r, t)=\frac{T\left(r_{o}, t\right)-T_{\infty}}{T_{i}-T_{\infty}}=A e^{-\lambda^{2} \tau} \frac{\sin \left(\lambda_{1} \frac{r_{o}}{r_{o}}\right)}{\left(\lambda_{1} \frac{r_{o}}{r_{o}}\right)} \\
=2.1 e^{-1.5^{2} \times 0.0421 \frac{\sin (1.5 \mathrm{rad})}{1.5}}=0.4992 \\
\frac{T\left(r_{o}, t\right)-(-6)}{18-(-6)}=0.4992 \\
\therefore T(r, t)=2.985^{\circ} \mathrm{C}
\end{gathered}
$$


The temperature at the radius, $r=0.889 \mathrm{~m}$ becomes:

$$
\begin{gathered}
\theta(r, t)=\frac{T\left(r_{o}, t\right)-T_{\infty}}{T_{i}-T_{\infty}}=A e^{-\lambda^{2} \tau} \frac{\sin \left(\lambda_{1} \frac{r_{o}}{r_{o}}\right)}{\left(\lambda_{1} \frac{r_{o}}{r_{o}}\right)} \\
=1.5 e^{-1.5^{2} \times 0.0421} \frac{\sin \left((1.5 \mathrm{rad})\left(\frac{0.889}{0.1}\right)\right)}{(1.578)\left(\frac{0.889}{0.1}\right)}=0.5950 \\
\frac{T\left(r_{o}, t\right)-(-6)}{18-(-6)}=0.5950 \\
\therefore T(r, t)=7.685^{\circ} \mathrm{C}
\end{gathered}
$$

\section{ANALYSIS WITH MEASURED PROPERTIES}

In this second part of the theoretical calculation, the watermelon is spherical in shape and the heat conduction in the fruit is one-dimensional because of symmetry about the midpoint. The thermal properties are constant and are that of water. The heat transfer coefficient is considered constant and uniform over the entire surface. Properties: The properties of the watermelon are considered at the average temperature of about $5^{\circ} \mathrm{C}$ from the literature with $\mathrm{k}=0.59 \mathrm{~W} / \mathrm{m} .{ }^{\circ} \mathrm{C}$ and

$$
\alpha=\frac{k}{\rho C_{p}}=\frac{.59}{(1025 \times 3926)}=1.46 \times 10^{-6} \frac{\mathrm{m}^{2}}{\mathrm{~s}}
$$

The Biot number is obtained as below:

$$
B i=\frac{h \times r_{o}}{k}=\frac{\left(15 \frac{W}{m^{\circ} \mathrm{C}}\right)(0.1 m)}{0.59 \frac{W}{m^{\circ} \mathrm{C}}}=1.694
$$

The constants $\lambda_{1}$ and $A_{1}$ corresponding to this Biot number are from the cengel handbook [19], where $\lambda_{1}=1.5$ and $A_{1}=2.1$. The Fourier number is

$$
\tau=\frac{\alpha t}{L^{2}}=\frac{\left(1.46 \times 10^{-6} \frac{\mathrm{m}^{2}}{\mathrm{~s}}\right)(3926 \mathrm{~s})}{0.1 \mathrm{~m}^{2}}=0.4552
$$

Therefore, the one-term approximate solution is applicable. Then the temperature at the surface of the watermelon becomes: 


$$
\begin{gathered}
\theta(r, t)=\frac{T\left(r_{o}, t\right)-T_{\infty}}{T_{i}-T_{\infty}}=A e^{-\lambda^{2} \tau} \frac{\sin \left(\lambda_{1} \frac{r_{o}}{r_{o}}\right)}{\left(\lambda_{1} \frac{r_{o}}{r_{o}}\right)} \\
=2.1 e^{-1.5^{2} \times 0.4552 \frac{\sin (1.5 \mathrm{rad})}{1.5}}=0.521 \\
\frac{T\left(r_{o}, t\right)-(-6)}{18-(-6)}=0.521 \\
\therefore T(r, t)=6.504^{\circ} \mathrm{C}
\end{gathered}
$$

The temperature at the radius, $r=0.889 \mathrm{~m}$ becomes:

$$
\begin{aligned}
& \theta(r, t)=\frac{T\left(r_{o}, t\right)-T_{\infty}}{T_{i}-T_{\infty}}=A e^{-\lambda^{2} \tau} \frac{\sin \left(\lambda_{1} \frac{r_{o}}{r_{o}}\right)}{\left(\lambda_{1} \frac{r_{o}}{r_{o}}\right)} \\
& =1.5 e^{-1.5^{2} \times 0.4552} \frac{\sin \left((1.5 \mathrm{rad})\left(\frac{0.889}{0.1}\right)\right)}{(1.578)\left(\frac{0.889}{0.1}\right)}=0.692 \\
& \frac{T\left(r_{o}, t\right)-(-6)}{18-(-6)}=0.692 \\
& \therefore T(r, t)=10.608^{\circ} \mathrm{C}
\end{aligned}
$$

\begin{tabular}{|c|c|c|c|c|c|c|}
\hline \multirow[t]{2}{*}{ Location } & \multicolumn{2}{|c|}{$\begin{array}{c}\text { Temperature } \\
\left({ }^{\circ} \mathrm{C}\right)\end{array}$} & \multirow[t]{2}{*}{$\begin{array}{l}\text { Time } \\
(\mathrm{min})\end{array}$} & \multirow{2}{*}{$\begin{array}{c}\text { Room } \\
\text { Temperature } \\
\left({ }^{\circ} \mathrm{C}\right)\end{array}$} & \multirow{2}{*}{$\begin{array}{c}\text { Freezer } \\
\text { Temperature } \\
\left({ }^{\circ} \mathrm{C}\right)\end{array}$} & \multirow{2}{*}{$\begin{array}{l}\text { Weight of } \\
\text { the fruit } \\
\text { (lb) }\end{array}$} \\
\hline & Initial & $\begin{array}{l}\text { After } \\
\text { Cooling }\end{array}$ & & & & \\
\hline $\begin{array}{l}\text { Outer } \\
\text { Boundary }\end{array}$ & 18 & 6.9 & 52 & $20.8^{\circ} \mathrm{C}$ & $-6^{\circ} \mathrm{C}$ & 15.28 \\
\hline $\begin{array}{l}\text { Bottom of } \\
\text { the rind }\end{array}$ & 17 & 11.9 & 52 & $20.8^{\circ} \mathrm{C}$ & $-6^{\circ} \mathrm{C}$ & 15.28 \\
\hline
\end{tabular}

\section{EXPIREMENTAL DATA}

The temperature details measured from the experiment across the radius of the watermelon are recorded in the table below.

Table 1 The temperature obtained from the experiment across the radius of the watermelon.

\section{RESULTS AND DISCUSSION}

The results obtained from the theoretical calculations are compared with the experimental results as shown in the Fig. $1 \&$ Fig. 2. As seen in Fig. 1, the temperature drop across the thickness of the rind is changing for the different methods. The temperature drop is maximum of $5^{\circ} \mathrm{C}$ for the experimental measurement. It decreases to $4.7^{\circ} \mathrm{C}$ for the method that had inputs from the literature where as it reaches a minimum of $4.1^{\circ} \mathrm{C}$ for the theoretical calculation based on the assumed water properties for the watermelon. This variation in the 
temperature drop indicates a higher thermal conductivity and diffusivity of the rind than that of water. The same trend is reflected on the heat transfer rate for these methods as shown in the Fig. 2.

\section{Temperature distribution across the watermelon}

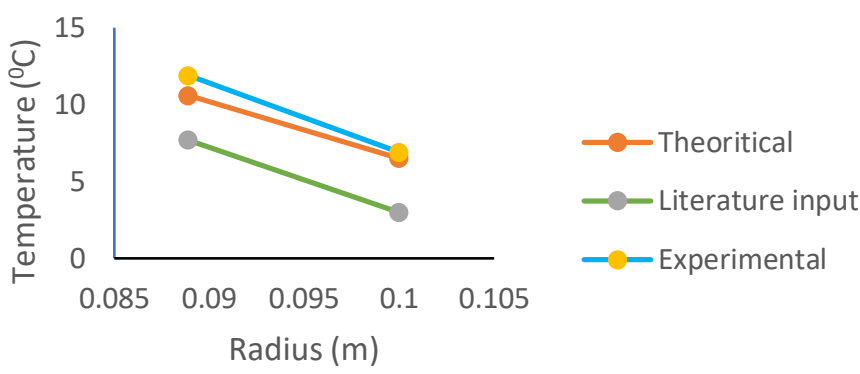

Fig. 2 The temperature distribution of watermelon across the radius with time.

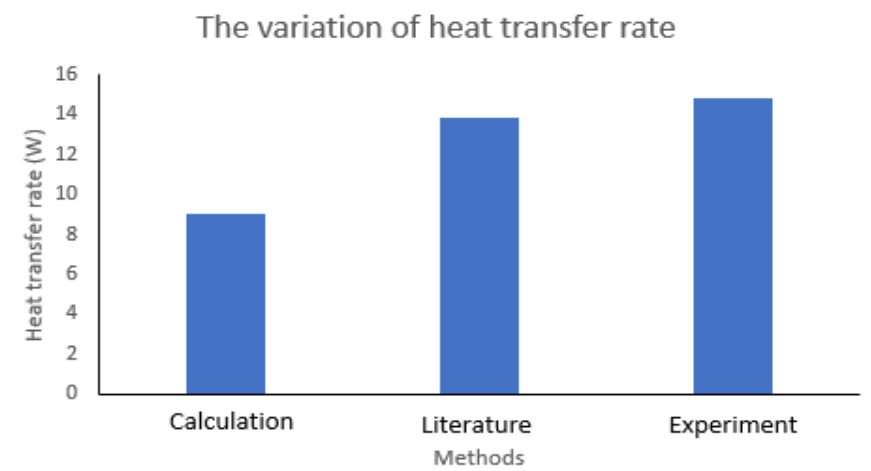

Fig. 3 The variation of heat transfer rate for different approaches.

\section{CONCLUSION}

In this study, the temperature distribution across the radius of a watermelon was measured, experimentally, for a transient cooling process with a surrounding temperature of $-6^{\circ} \mathrm{C}$. The experimental data were compared with the theoretical calculations with the assumed thermal properties of water for the watermelon and thermal properties from the literature. The results show that the temperature drop across the rind of the fruit is maximum for the experimental observation whereas it is minimum for the theoretical calculation based on assumed water properties for the watermelon. This change in the temperature drop is significant while designing the thermal process during the storing and transportation of these fruits. A further experimental investigation in the thermal properties of the rind of the watermelon will be part of the future work.

\section{NOMENCLATURE}

\begin{tabular}{|c|c|c|}
\hline $\mathrm{T}$ & Temperature & ${ }^{0} \mathrm{C}$ \\
\hline $\mathrm{C}_{\mathrm{p}}$ & Specific heat & $\mathrm{K}$ \\
\hline$k$ & Thermal conductivity & $\mathrm{W} /(\mathrm{mK})$ \\
\hline$\alpha$ & Diffusivity & $\mathrm{m}^{2} / \mathrm{s}$ \\
\hline$B i$ & Biot number & - \\
\hline
\end{tabular}




\begin{tabular}{|c|c|c|}
\hline$\rho$ & Density & $\mathrm{kg} / \mathrm{m}^{3}$ \\
\hline $\mathrm{t}$ & Time & $\mathrm{s}$ \\
\hline $\mathrm{r}$ & Radius & $\mathrm{m}$ \\
\hline $\mathrm{h}$ & Heat transfer coefficient & $\mathrm{W} /\left(\mathrm{m}^{2} \mathrm{~K}\right)$ \\
\hline $\mathrm{A}_{1}$ & Constant & - \\
\hline$\tau$ & Fourier number & - \\
\hline$\lambda$ & Constant & - \\
\hline
\end{tabular}

\section{REFERENCES}

[1] Dincer, I. (1991a). A simple model for estimation of the film coefficients during cooling of certain spherical foodstuffs with water. Int. Comm. Heat Mass Transfer, 18431-43.

[2] Dincer, I. (19916). Experimental and theoretical heat and mass transfer studies on the forced-air precooling of spherical food products. MSc thesis, Mechanical Engineering Department, Yildiz University, Istanbul. Dincer, I. (1992).

[3] Ibrahim Dincer, Methodology to determine temperature distributions in cylindrical products exposed to hydrocooling. Int. Comm. Heat Mass Transfer, 19, 359-71. May-June 1992, Pages 359-371

[4] Stela L.R.MendonçaaCelso R.B.FilhobZ.E.da Silvac,Transient conduction in spherical fruits: method to estimate the thermal conductivity and volumetric thermal capacity, Journal of Food Engineering,volume 67, Issue 3, April 2005, Pages 261-266

[5] Showwalter R. , Watermelon color as affected by maturity and storage, Proceedings of the Florida State Horticultural Society 1960 Vol.73 pp.289-93 Sumriddetchkajorn, S. and Somboonkaew, A., "TAD2: the first truly non- intrusive lie detection system deployed in real crime cases," Proc. SPIE 7854, 78540Z (2010).

[6] Dow, A.T., Segall, R.H., Hopkins, D.L., Elmstrom, G.W., 1979. Effects of storage temperature and field fungicide treatments on decay of Florida watermelons. Proc. Fla. State Hort. Soc. 91:149- 150.

[7] GAEO (General of Agricultural Economics organization) - Ministry of Agriculture and Land Reclamation, 2013. Acreage statistics and vegetable production in the Arab Republic of Egypt

[8] THERMAL CONDUCTIVITY OF PEACH, RASPBERRY, CHERRY AND PLUM JUICES AS A FUNCTION OF TEMPERATURE AND CONCENTRATION-Journal of Food Process Engineering 29 (2006) 304-326.

[9] Koocheki, A., Razavi, S.M.A., Milani, E., Monghadam, T.M., Alamatiyan, S., Izadkhah, S., 2007. Physical properties of watermelon seed as a function of moisture content and variety. Int. Agrophysics, 21: 349-359.

[10] Perkins-VeazieJ.KCollins, Flesh quality and lycopene stability of fresh-cut watermelon Postharvest Biology and Technology,Volume 31, Issue 2, February 2004, Pages 159-166

[11] Ba wa A.S. and Bains G.S., 1977. Integrated processing of watermelons for juice and seed. Indian Food Packer, 31,12

[12] Hanan M.A.Al-Sayeda Abdelrahman R.Ahmedb, Utilization of watermelon rinds and sharlyn melon peels as a natural source of dietary fiber and antioxidants in cake, Annals of Agricultural Sciences, volume 58, Issue 1, June 2013, Pages 83-95

[13] El-Raie, A. E. S., El Sahrigi, A. F., Mosa, M. M. (1998). Engineering factors affecting the development of grading machine for citrus. Integrated local and foreign manufacturing of agriculture. In Equipment and machinery 6th conference of Misr society of Agric. Eng., 21-22 October 1998 (pp. 79-90).

[14] Physical and mechanical properties of some Egyptian onion cultivars A.H. Bahnasawy *, Z.A. El-Haddad, M.Y. El-Ansary, H.M. Sorour, Journal of Food Engineering 62 (2004) 255-261

[15] Hardenburg, R.E., Watada, A.E., Wang, C.Y., 1986. The commercial storage of fruits, vegetables, and florist and nursery stocks. USDA Agr. Hdbk. 66. Vadivambal R, Jayas DS, Chelladurai V, White NDG (2007)

[16] Picha, D.H., 1986. Postharvest fruit conditioning reduces chilling injury in watermelons. HortScience 21(6):14071409

[17] Dongxiao Sun-Waterhouse, Juan Chen, Cheryll Chuah, Reginald Wibisono, Laurence D. Melton, William Laing, Lynnette R Ferguson \& Margot A Skinner (2009) Kiwifruit-based polyphenols and related antioxidants for functional foods: kiwifruit extract-enhanced gluten-free bread, International Journal of Food Sciences and Nutrition, 60:sup7, 251-64, DOI: 10.1080/09637480903012355

[18] Cengel, Heat and Mass Transfer A Practical Approach, $3^{\text {rd }}$ Edition, (2006). McGraw-Hill Education, NY.

[19] Priyanto et.al , Thermal properties of melon [1992], 